\title{
Suposições: o que você sabe sobre design e risco?
}

\author{
Assumptions: what do you know about design and risk?
}

\section{WOLFGANG, Simone Medina I Doutoranda em Design \\ Departamento de Artes e Design I PUC Rio \\ simone.wolfgang@terra.com.br}

\section{PORTINAR, Denise Berruezo I Pós Doutora}

Departamento de Artes e Design - PUC Rio denisep@puc-rio.br

\section{Resumo}

Este artigo mostra aspectos da trajetória histórica e social da epidemia de HIV/Aids através da exposição de alguns cartazes de prevenção. Essas peças servem como pano de fundo para a condução de uma discussão um pouco mais ampla: o papel do designer enquanto projetista, como um mero reprodutor de discursos prontos. A partir dessa discussão, pretendemos propor a ampliação dos horizontes de atuação profissional do designer de forma a pensar novas propostas e novos formatos para as políticas de prevenção e saúde. Os cartazes apresentados aqui foram fornecidos pela ONG San Francisco Aids Foundation?.

Palavras Chave: Design gráfico. Prevenção a AIDS. HIV.

\section{Abstract}

This article shows a little bit of the historical and social path of the HIV/Aids epidemic through the exhibition of some prevention posters. The choice of these pieces were done in a way to help the conduction of a bigger argumentation: the role of the designer (the one's that make those campaigns) as a simple reproducer of known discourses. Therefore the bigger goal here is to propose the enlargement of the fields and the boundaries for the professional act of the designer in a way of thinking new proposals and new ways to deal with the politics of prevention and health. The campaigns presented here where given by the ONG San Francisco Aids Foundation.

Keywords: Graphic design. Aids prevention. HIV. 


\section{INTRODUÇ̃̃O'}

Qual é a relação que pode ser estabelecida entre a concepção e o

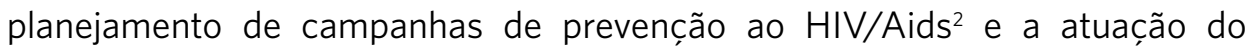
designer? Na prática, essa relação pode ser mínima. As campanhas são elaboradas em esferas externas ao campo de atuação do designer (em agências de publicidade, por demanda de órgãos governamentais ligados a políticas de saúde), e o designer só é convocado para atuar na materialização final das peças (projeto gráfico, elaboração de layout, etc.) - recebendo, para tal, um "briefing" constituído por conceitos já estabelecidos e decisões tomadas anteriormente. Em suma, a sua intervenção efetiva nas campanhas é restrita à execução de orientações pensadas por outrem.

Se esse é o limite e o fim de toda possibilidade real de atuação do designer na elaboração de produtos e sistemas concebidos para intervirem de alguma maneira na sociedade, se a contribuição deste profissional é restrita a sua expertise técnica em materializar a demanda alheia, cabe perguntar qual é o sentido de uma formação de nível superior em design, e mais ainda, qual é o sentido da pesquisa e da formação em design a nível de pós-graduação stricto sensu.

A finalidade última da pesquisa referida neste artigo - pesquisa conduzida em um programa de pós-graduação stricto sensu em design - é justamente a de questionar os limites e as possibilidades da pesquisa acadêmica em design, sem perder de vista a concretude de sua prática. Assim, esta pesquisa aposta na ampliação do saber (teoria) e das possibilidades de atuação (prática) do designer na elaboração de campanhas de prevenção ao HIV/Aids voltadas para o público homossexual masculino ${ }^{3}$. A escolha por essa esfera de atuação se deu em função das experiências anteriores de pesquisadora e orientadora com a temática do HIV/Aids e da homossexualidade, e da observação de reações e questionamentos levantados no universo homossexual quanto à adequação e a eficácia das diversas campanhas de prevenção existentes.

A pesquisa vem sendo feito de acordo com o paradigma da pesquisa

1 Este artigo faz parte de pesquisa de doutorado realizada na PUC-Rio, financiada pela CAPES e FAPERJ.

2 A grafia do termo Aids será utilizada neste artigo somente com a primeira letra em maiúsculo. Essa opção se deu pela demanda do movimento social de pessoas vivendo com o vírus que acredita que a mudança gramatical desloca o foco da patologia para a pessoa vivendo com a síndrome. A nova terminologia foi adotada inclusive pelo Ministério da Saúde.

3 Apesar das muitas alternativas ao termo homossexualidade, como homoerotismo ou homo-orientados, o termo homossexualidade me é mais simpático e acredito que a compreensão do texto se torne mais fácil ao utilizá-lo. 
qualitativa, em que as questões e os métodos estão permanentemente sujeitos às alterações trazidas pelo próprio desenrolar da pesquisa. Todavia existe um conjunto de ações metodológicas que permanecem estáveis e norteiam todo o processo: o levantamento e a análise comparativa das campanhas existentes e o papel nelas desempenhado pelo designer, as entrevistas com o chamado "público-alvo" dessas campanhas, o diálogo com profissionais atuantes na área da saúde e da prevenção. Neste artigo, será apresentada uma parte dessas ações: o estabelecimento de bases para uma análise comparativa das campanhas existentes através do exame de alguns cartazes e do contexto histórico de sua produção.

\section{METODOLOGIA}

Neste artigo, mostramos uma análise realizada com uma seleção de quatorze cartazes dentre os cedidos por uma fundação de combate a Aids que atua desde 1983 nos Estados Unidos: a San Francisco Aids Foundation ${ }^{4}$. A escolha desse material aconteceu primeiramente porque a fundação produz campanhas de prevenção desde os primeiros anos da epidemia, que está acessível e em boas condições para ser estudado. O acervo da fundação é vasto, longevo e próprio. Além disso, e o acesso as peças é livre, assim como sua reprodução, o que facilita muito na hora da escolha do que é pertinente a pesquisa, pois são maiores as opções. Isso nem sempre é possível ao se recolher campanhas de prevenção de diferentes origens, pois a temática delas pode variar bastante entre si. O objetivo dessa análise é o de levantar as relações existentes entre as mensagens veiculadas, as formas de veiculação escolhidas e o momento histórico da epidemia em que se inserem. No que concerne os objetivos "maiores" da pesquisa referida aqui, consideramos que o conhecimento dessas relações é um dos fundamentos necessários para a instrumentalização do designer envolvido na produção de tais campanhas e a conseqüente ampliação de sua esfera de atuação nas mesmas.

A seleção dos cartazes analisados procurou apresentar para o leitor a formação de um imaginário ligado ao HIV/Aids nas diferentes épocas da epidemia. Essa é uma maneira de ilustrar como a concepção das campanhas estava diretamente ligada a condução social da epidemia, e ao gerenciamento das informações fornecidas pela mídia e a gestão dos riscos em saúde.

Para poder localizar temporalmente o evento, e ilustrar o contexto e

4 A San Francisco Aids Foundation é uma ONG Norte Americana que trabalha com cuidados, apoio e prevenção a Aids, mais informações podem ser obtidas no site: http://www.sfaf.org/ 
as necessidades que levaram ao surgimento das campanhas de prevenção, começaremos nossa exposição com um breve resumo histórico da epidemia; para então, apresentarmos os cartazes que estão dispostos numa espécie de "linha do tempo", exibidas de acordo com o ano de cada veiculação.

\section{HIV-Aids: um breve histórico}

Em 1983, o vírus da Aids foi isolado pelos pesquisadores Robert Gallo nos EUA e Luc Montagnier, na França. No ano de 1986, um comitê internacional recomendou o termo HIV (vírus da imunodeficiência humana) para denominálo.

Alguns anos antes, no começo dos anos de 1980, em várias cidades ao redor do mundo, pessoas doentes procuravam prontos-socorros com sintomas bastante específicos e semelhantes: pneumonia do tipo pneumocystis carinii provocada por um microorganismo que costuma atacar organismos debilitados ou com baixa imunidade - e sarcoma de kaposi - um tipo de câncer que afeta as paredes dos vasos linfáticos.

Em 1981 pesquisadores do CDC (Centers for Disease Control and Prevention) em Atlanta nos Estados Unidos, haviam descrito pela primeira vez a Síndrome da Imunodeficiência Adquirida, contudo, sem nomeá-la cientificamente.

Enquanto isso, as informações divulgadas pela imprensa propiciavam o aparecimento de novas categorias subjetivas ligadas à Aids, como é o caso do chamado "grupo de risco" que englobava a priori homossexuais masculinos e usuários de drogas; mais tardiamente as profissionais do sexo também foram inclusas. Outra forma de estigma propagada pela imprensa foram as primeiras denominações da doença veiculadas publicamente. A utilização de termos estigmatizantes como peste gay, e prática de apontar supostos culpados pela epidemia (homossexuais, profissionais do sexo, usuários de drogas injetáveis) não eram incomuns nos primeiros anos da epidemia.

Nenhuma doença provocou, nos últimos anos, tantas reações de angústia e fascínio como a Aids ao misturar os medos e os tabus milenares de epidemia, homossexualidade e morte. Suas vias de transmissão pelo sangue e pelo esperma são carregadas de ligação com as idéias de pureza, procriação e reprodução social. (POLLAK, 1990, p. 11). 
O vírus HIV e as mortes causadas por ele faziam surgir novas configurações para a homossexualidade masculina. Primeiramente "delatando" uma série de homens que viviam uma existência homossexual a parte e/ou se relacionavam também com pessoas do sexo oposto, que foram obrigados a revelar essa sexualidade oculta devido o caráter denunciador da doença.

Enquanto a epidemia se alastrava, a falta de informação sobre a doença fazia a sociedade em geral lidar de forma bastante temerosa perante a Aids e seus doentes. Por um lado havia o desespero dos médicos nos primeiros anos da epidemia. Por outro, uma crença por parte de alguns de que a doença se tratava de uma espécie de "castigo divino" àqueles que de alguma forma eram desviantes, seja praticando o sexo homossexual ou usando drogas injetáveis. $O$ que também se refletia no tratamento médico de alguns doentes de Aids e nas formas como a sociedade lidava com esse tipo de ameaça.

\begin{abstract}
Enquanto categoria de construção da realidade social, a definição da Aids e de seu contágio tornou-se objeto de concorrência científica e lutas sociais conduzidas na maioria das vezes por intermédio dos meios de comunicação de massa. Até a descoberta do vírus e a comprovação de sua participação no desencadeamento da doença em 1983-1984, estabeleceu-se, na falta de um único modelo etiológico comumente aceito nos meios científicos, uma construção estatística muito rígida de "grupos de risco", o que gerou uma profusão de hipóteses e interpretações muitas vezes contraditórias. (POLLAK, 1990, p. 12).
\end{abstract}

Somente em 1985 chegava ao mercado um teste sorológico conhecido como ELISA para o diagnóstico da infecção pelo HIV. Algumas drogas experimentais eram utilizadas sem sucesso, o tratamento para a doença era muito difícil e o primeiro medicamento com eficácia relativa no combate ao vírus só estava disponível no final dos anos de 1980 com a introdução do AZT.

Nos anos que se seguiram, organizações não governamentais criaram uma série de campanhas voltadas para a prevenção da Aids/HIV. Entretanto o aparelho burocrático e governamental de diversos países produzia campanhas ineficazes e imprecisas; alguns teóricos como Michel Pollack atribuem isso aos tabus associados à doença. Muitas vezes a linguagem utilizada não era clara e pouco se falava sobre as formas de contato especialmente no que dizia respeito ao contagio por via sexual.

Muitos anos se passariam até a propagação das práticas de sexo seguro ou "safersex", que consiste não somente no uso da camisinha, mas também na 
diminuição do número parceiros e pelo incentivo de práticas sexuais "menos perigosas" que não necessariamente envolvam penetração. Valendo ressaltar aqui que muitas das campanhas de prevenção eram veiculadas informalmente entre grupos de amigos.

Em meados dos anos de 1990 uma série de estudos foi realizada em torno de um novo grupo de drogas para o tratamento da infecção, os chamados inibidores da protease. Estas drogas demonstraram potente efeito anti-viral isoladamente ou em associação com drogas do grupo do AZT (daía denominação "coquetel"). Houve então uma diminuição da mortalidade imediata e melhora dos indicadores de imunidade. Ou seja, aumento do número das células CD4 e a recuperação de infecções oportunistas mais comuns nos pacientes de Aids.

A partir desse momento muitos apostaram em uma cura. Entretanto, logo se percebeu que o tratamento não eliminava o vírus do organismo dos pacientes apesar de alguns deles apresentarem uma carga viral muito próxima a zero. Somando-se a isso, o tratamento tem custos econômicos e emocionais muito elevados, em alguns casos, um grande número de comprimidos deve ser ingerido diariamente - podendo chegar a mais de 20 por vez - com rígidos controles de horário a fim de garantir a total eficácia do medicamento.

\section{Produzindo novas imagens: as campanhas de prevenção}

Com o passar dos anos e o decorrer da epidemia da Aids tendo por consequência um número constantemente crescente de vítimas, os aparelhos governamentais aos poucos foram se conscientizando que os recursos médicos disponíveis não levariam a cura, o que gerava a necessidade de criação de outras formas de combate ao vírus. É neste espaço que entra a informação, na forma de campanhas de prevenção.

Em meados dos anos de 1980 surgiram a maioria dos programas estatais de controle e prevenção da Aids, como é o caso do brasileiro Programa Nacional de Prevenção de DST/Aids criado em 1987. Além das campanhas de prevenção, aconteciam outras formas de manifestação através de imagens. Pessoas de todo mundo começavam a se unir procurando criar formas de protesto e ao mesmo tempo amenizar a dor causada pela perda de amigos e parentes. O resultado desses protestos acontece através de uma produção imagética muito ampla e variada; Criando-se novos referenciais imagéticos para ligados a epidemia. 


\title{
As campanhas de prevenção
}

As campanhas de prevenção e cuidados com os doentes de HIV/Aids foram criadas para procurar instruir e, de alguma forma, procurar impedir o avanço da doença. Como a Aids está diretamente associada a questões que são tabus para muitas culturas - a sexualidade, o ato sexual, homossexualidade, prostituição e o uso de drogas ilícitas - o aparelho burocrático de muitos países embargou diversas campanhas de prevenção ao vírus.

Outra questão problemática no que diz respeito à veiculação de campanhas de prevenção são as diferenças culturais e sociais que distinguem as pessoas de uma mesma sociedade. Cada segmento social tem necessidades específicas, existem pessoas com níveis diferentes de escolaridade e de acesso à informação. Além disso, as práticas sexuais de cada grupo e as formas de contágio diferem.

No Brasil, os primeiros informes sobre a doença eram constituídos por avisos transmitidos pela televisão na forma de reclames rápidos e cartazes colados pelas grandes cidades, descrevendo sintomas de forma breve e direcionando os doentes a procurarem um médico caso apresentassem qualquer sintoma.

\begin{abstract}
No início, elas possuíam um padrão uniforme e não tinham sensibilidade para as diferenças culturais e etárias. As campanhas governamentais eram agressivas e contribuíam para disseminar uma postura discriminatória em relação ao doente e pouco esclarecedora em relação à doença. Usavam frases impactantes como: 'A Aids mata!, 'Aids, você precisa saber evitar' ou ainda ' Quem vê cara não vê Aids' (NASCIMENTO, 1997, p.171)
\end{abstract}

Logo após a criação do programa nacional em DST/Aids as campanhas de prevenção brasileiras enfatizavam basicamente o caráter mortal da doença e não as suas formas de prevenção. Por muito tempo o medo foi a personagem principal das campanhas de prevenção.

O filme "Arlequim" de 1988, que fazia parte da campanha "Quem vê cara não vê Aids", uma série de 4 filmes com duração de 60 segundos. "Arlequim" foi o primeiro a realizar uma associação com o carnaval, período que depois foi escolhido como data fixa para o lançamento das campanhas de prevenção. Nele, a imagem de um folião vestido de arlequim acompanha uma narração em off e 
o espectador assiste a uma seqüência de degradação. Ao longo de um minuto o palhaço, único personagem do filme, perde o brilho, a alegria e a saúde e termina em um quarto de hospital debilitado, sob um crucifixo pendurado na parede. A fala menciona "uma outra face da folia que não tem nada de iluminada". O tom é ameaçador e produz o apelo emocional. O slogan "quem vê cara não vê Aids", é desenvolvido no texto que dispara: - "é a face trágica de uma doença mortal, chamada Aids. Lembre-se de que a Aids mata sem piedade. E está se espalhando por aí. (LEMOS, 2006, p.52)

Enquanto isso em vários países as pessoas queixavam-se da falta de precisão das informações contidas nas campanhas de prevenção ao HIV/Aids, e do pouco esclarecimento sobre as reais formas de contágio.

No começo dos anos de 1990, as primeiras campanhas de prevenção enfatizando a prática do "safersex", ou sexo seguro, são veiculadas no Brasil e no mundo. A MTV então se torna pioneira na divulgação de campanhas direcionadas a jovens, sempre com uma preocupação em direcioná-las para os diferentes grupos sociais, enfatizando suas diferenças, e as formas de prevenção.

A descoberta do coquetel em meados dos anos de 1990 teve como principal conseqüência a diminuição da taxa de mortalidade dos doentes, fato que, por conseguinte altera mais uma vez a linguagem visual das campanhas e o seu conteúdo. Isso ocorria de diversas formas, mas principalmente se estimulava a testagem, já que o diagnóstico precoce facilita o tratamento e melhora a saúde do portador.

É neste momento também, que o infectado passa a ser o destinatário de campanhas de prevenção e cuidados, em campanhas que esclarecem sobre a necessidade do uso continuo do preservativo para evitar re-infecções além de falar sobre os efeitos colaterais dos antiretrovirais.

Para termos uma idéia mais concreta do que acabou de ser dito, os próximos tópicos mostram uma série de campanhas procurando situar para o leitor a condução social da epidemia nas suas diferentes etapas e o tratamento gráfico que era dado a essas peças.

\section{A Prevenção no San Francisco AIDS Foundation entre 1983 e 2002}


O conteúdo das campanhas de prevenção e cuidados em HIV/Aids sempre estiveram atreladas aos discursos relacionados ao vírus no decorrer da epidemia.

No começo, por exemplo, muito se especulava sobre as formas de contaminação, mas na verdade pouco se sabia, além disso, havia uma negociação constante sobre o que deveria ser dito, e os tabus ligados ao vírus o que influenciava diretamente o conteúdo das campanhas.

Pode-se especular que existiriam duas correntes: uma mais informativa e a outra mais "alarmista", ou mais voltada para a intimidação. A primeira imagem ${ }^{5}$ apresentada aqui é um bom exemplo do primeiro caso.

Na figura 1, vemos um cartaz que utiliza um fundo preto, fonte bold na cor vermelha, é uma chamada que pode ser rapidamente lida em poucos segundos. Esse é um formato típico dos primeiros reclames que alertavam sobre a doença. O nome da doença aparece em destaque, atrelado a mensagem "Aids, é o que você faz não quem você é". Não se veiculavam formas de contaminação nessa etapa, porém nesta campanha podemos ver uma coisa que era rara na época: a preocupação em ressaltar que qualquer pessoa pode se contaminar.

Já a figura 2 de 1985 segue o exemplo de modelo utilizado pela maioria das campanhas de prevenção do começo da epidemia. "ela tem os olhos do pai e a Aids da mãe" diz o cartaz. A atenção é toda voltada para esta mensagem. Não existe nenhum esclarecimento sobre formas de prevenção, apenas diz para quem está pensando em engravidar descobrir se é necessário fazer o teste. Outra campanha que seguia a mesma linha temática é a figura 3 "você e sua carteira de motorista terão a mesma data de expiração". Não existe nenhum tipo de reflexão mais profunda sobre o advento da epidemia neste tipo de iniciativa, também não se abordam as possíveis maneiras de se prevenir do vírus.

A maioria das campanhas desta época se esquivava da prevenção e apenas enaltecia o caráter mortal da doença, e/ou mantinha uma rotina de mensagens alarmistas.

5 Todas as imagens foram cedidas pelas respectivas ONG'S e têm permissão para utilização em publicações acadêmicas. 
Figura 1 - "it's what you do" (1984)

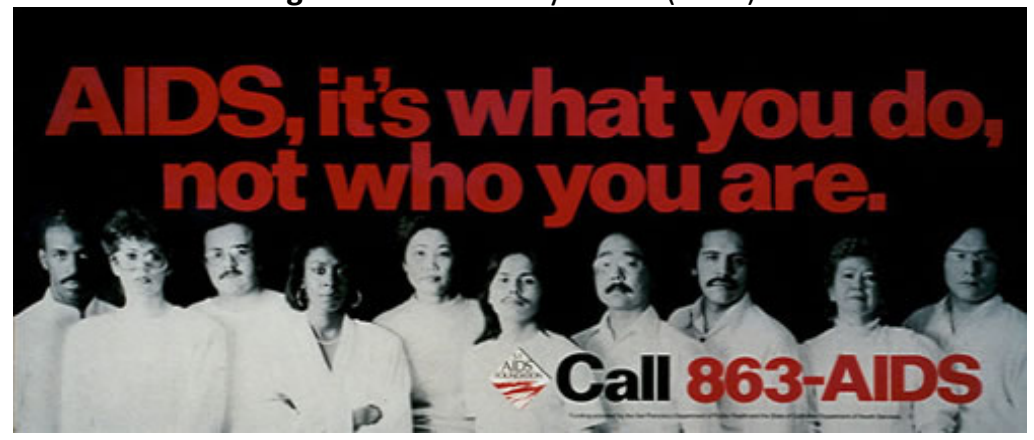

Fonte: San Francisco Aids Foundation (2012).

Figura 2 - "father's eyes" (1985)

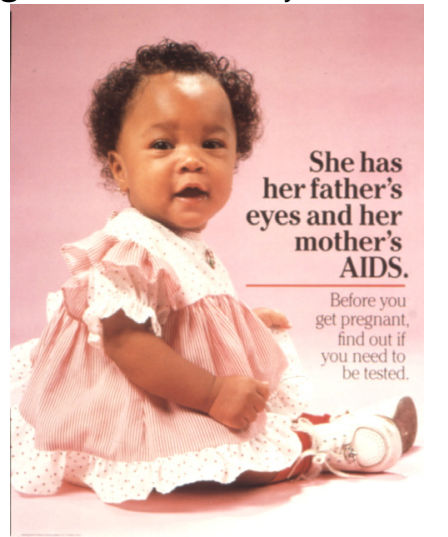

Fonte: San Francisco Aids Foundation (2012).

Figura 3 - "Drivers license" (1986)

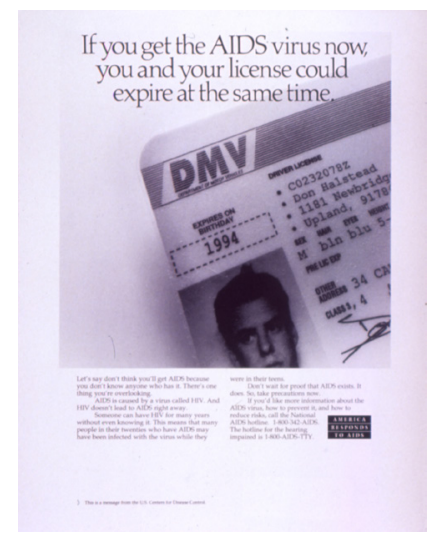

Fonte: San Francisco Aids Foundation (2012).

\section{Posso pegar AIDS bebendo do mesmo copo?}

Com o passar dos anos, expuseram-se a grande dificuldade em se 
obter um tratamento eficaz e até mesmo uma cura ou vacina em curto prazo, baseando-se no conhecimento médico disponível naquela época. Aos então, poucos vão surgindo os programas estatais de prevenção ao vírus, às formas de contaminação não são mais um mistério científico, e aos poucos se percebe o valor da informação; é neste momento também, que preocupação não é mais somente "não se contaminar", mas também procurar minimizar os estigmas e os mitos que foram criados em torno do vírus. Dois bons exemplos desse tipo de campanha podem ser vistos nas (figura 4) "algumas pessoas pensam que você pode pegar Aids de um copo. Você não pode." E na (figura 5) "nenhum desses atos transmitem a Aids" mostra o aperto de mão, o compartilhamento de talheres, o uso de vaso sanitário e o uso da maçaneta. O cartaz traz um número para maiores esclarecimentos sobre a doença, mas fica claro que este não é o objetivo principal.

Figura 4 - "Fight the fear" (1987)

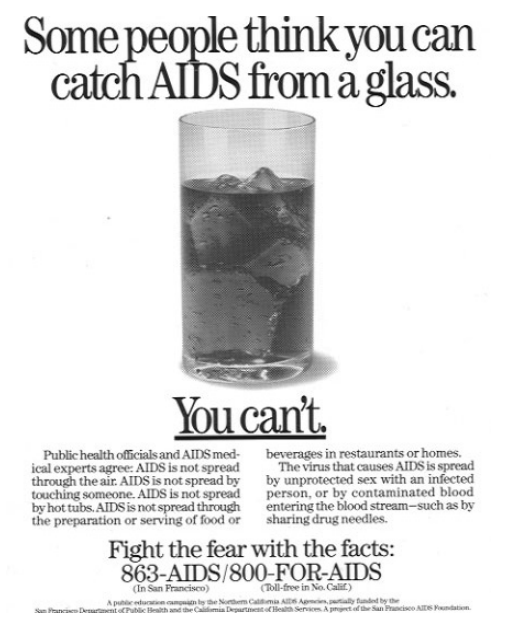

Fonte: San Francisco Aids Foundation (2012).

Figura 5 - None of this will give you Aids (1988)

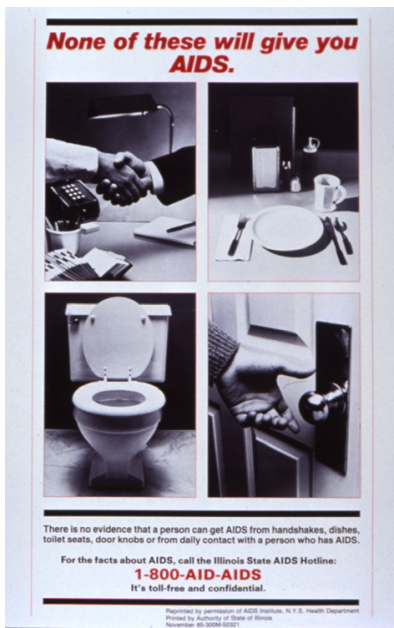

Fonte: San Francisco Aids Foundation (2012). 
Apesar das informações de prevenção constituírem uma questão de extrema importância, neste momento histórico ainda pouco se fala ou se mostra em relação às formas de contaminação; o foco parece ser a desmistificação dos grandes sensacionalismos ligados à epidemia.

A primeira campanha que mostra um preservativo de forma razoavelmente destacada é de 1988, e apesar da figura do preservativo, nada se fala sobre como ou porque se deve usá-lo. É campanha da (figura 6) que diz: "Necessidades da vida. Ligue 863-Aids".

Figura 6 - "necessities" (1988)

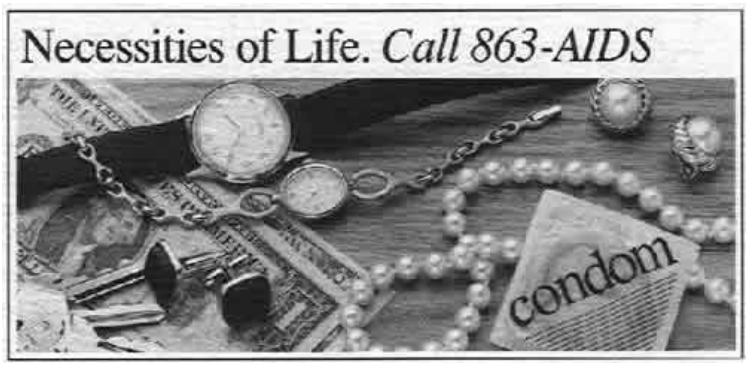

Fonte: San Francisco Aids Foundation (2012).

\section{Os anos 90}

As primeiras campanhas da década de 1990, já se diferenciavam bastante gráfica e conceitualmente daquelas existentes nos primeiros anos da epidemia. Em alguns países, já se pensava na importância de um espaço para a segmentação das campanhas, ou seja, algumas dessas peças procuravam atender as diferentes necessidades de prevenção dos diversos nichos da sociedade, como era o caso dos homossexuais masculinos. Curiosamente, a homogeneidade do material gráfico produzido ainda é uma das maiores críticas das ONGS aos órgãos governamentais que divulgam campanhas de prevenção do Brasil.

Um bom exemplo da segmentação das campanhas pode ser visto na (figura 7) "seja um homem borracha" em que o modelo da campanha está de joelhos em uma cama, vestindo somente uma cueca e com uma camisinha na mão. O texto do cartaz diz: "eu sei que os ativos pegam Aids. Mas não este aqui... eu uso camisinha todas as vezes, e você?".

Nos anos de 1990 a mensagem "A Aids mata" vai sendo aos poucos substituída por outras como: "use sempre camisinha", ou "faça sexo seguro" ou mais seguro, o conhecido como: "safer sex" que consiste não somente no uso 
da camisinha, mas também em práticas sexuais que significam menos risco como o sexo oral, por exemplo. Um exemplo da divulgação dessas práticas por campanhas de prevenção pode ser visto na (figura 8) que tem como título o texto "sexo oral é sexo mais seguro", seguido por uma série de dicas sobre o que fazer para se prevenir da contaminação.

Figura 7 - "be a rubberman"(1990)

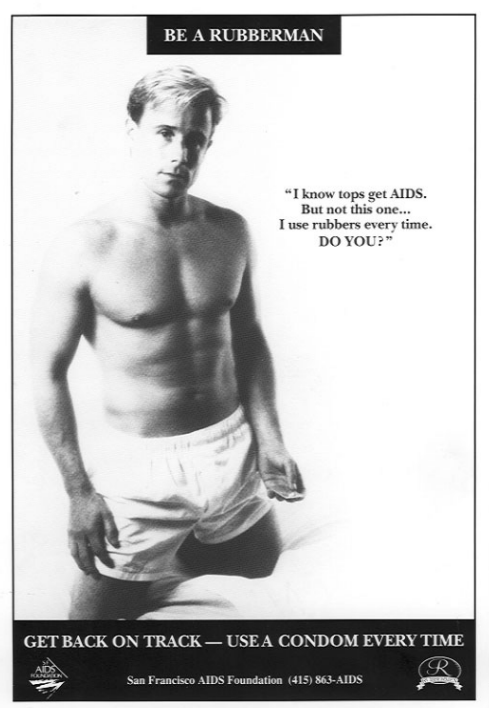

Fonte: San Francisco Aids Foundation (2012).

Figura 8 -"safer sex" (1993)

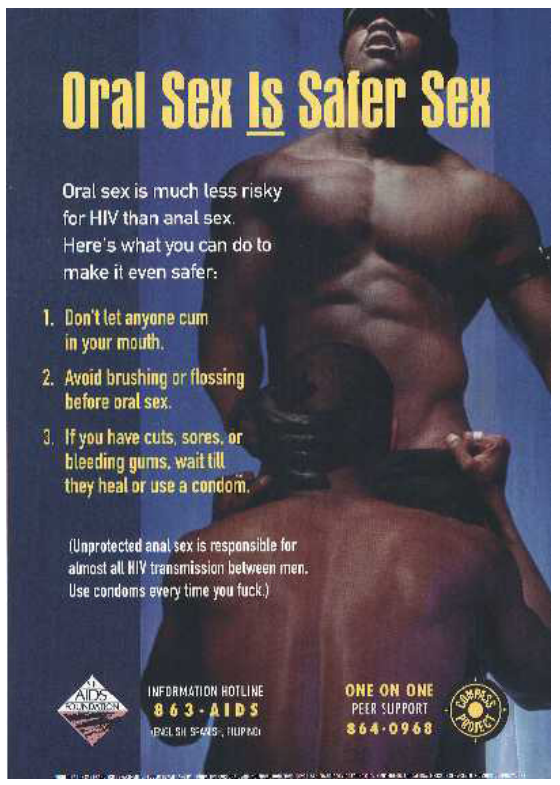

Fonte: San Francisco Aids Foundation (2012). 
A partir de meados da década de 1990, novos parâmetros ditavam as mensagens e a linguagem visual das campanhas de prevenção. Novamente eram veiculadas mensagens para os portadores do vírus, não só na tentativa de prevenir a estigmatização, mas também incentivando as pessoas a procurarem o teste e o diagnóstico precoce da doença. Como pode ser visto na (figura 9) de 1993 "esteja aqui para a cura" diz a campanha, a única da ONG voltada para mulheres homossexuais. É justamente nesta época que começam a surgir novas alternativas (ainda experimentais) de tratamento.

As primeiras campanhas que utilizavam imagens mais explicitas do ato sexual também datam desta época, como é o caso da (figura 10) "viva de amor e de gel a base de agua.".

Figura 9 -"be here for the cure" (1993)

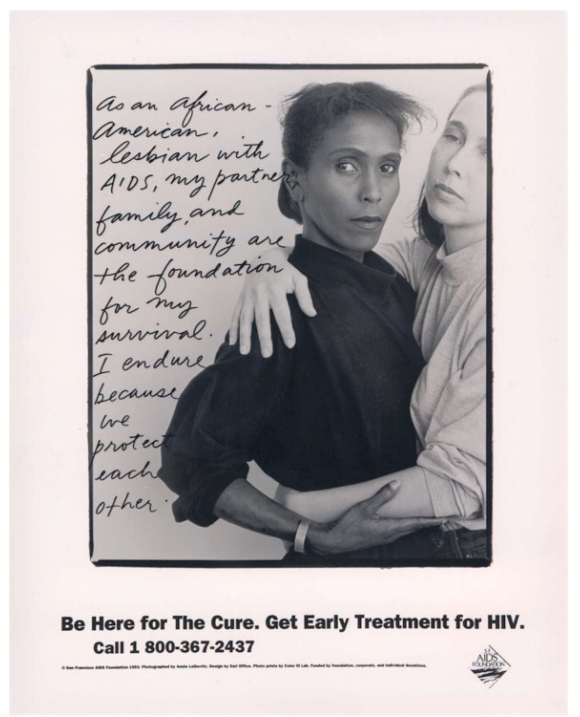

Fonte: San Francisco Aids Foundation (2012).

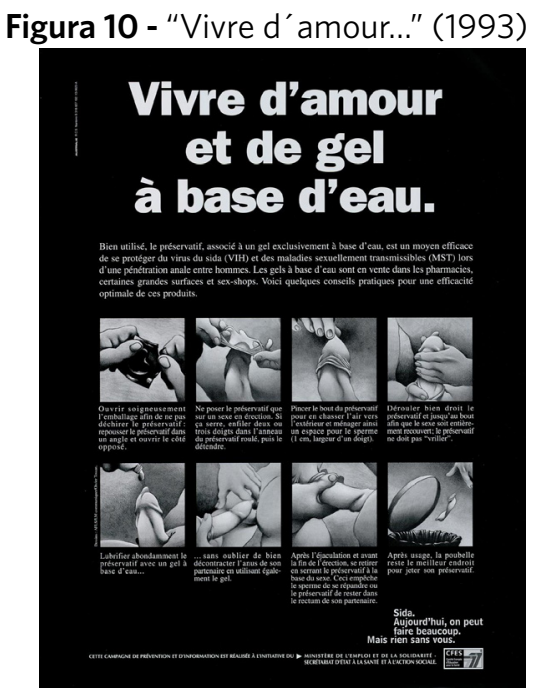

Fonte: San Francisco Aids Foundation (2012). 


\section{Um coquetel de novas possibilidades}

A descoberta dos então novos tratamentos utilizados em forma de "coquetel" e o impacto deste fato na vida dos que viviam com o vírus, criava toda uma nova demanda de prevenção. Surgem então campanhas que utilizam a eficácia do tratamento para estimular a procura pelo teste, o diálogo aberto entre parceiros, sobre sorologia ditando uma nova etapa onde viver muito com o HIV torna-se viável.

Curiosamente, a existência de um tratamento eficaz, aliada a um controle sociocultural deficiente da epidemia, abriu espaço para o surgimento de novas demandas de prevenção. Seja pela exacerbação de antigos estigmas ligados a epidemia como uma suposta restrição da circulação do vírus somente entre certas camadas da sociedade como os homossexuais masculinos e os profissionais do sexo; ou a crença na medicação como situação ideal para o controle do vírus, tornando as práticas preventivas acessórias uma vez que existiria um tratamento eficaz.

De fato, o surgimento do "coquetel" gerou toda uma nova necessidade em termos de prevenção. Neste momento surgiu a necessidade de se trabalhar a prevenção a partir de novos dados sobre o risco relativizando os dados. Isso pode ser visto na (figura 11) que mostra a imagem de dois homens em um ato sexual e o texto diz: "ele é apenas um pedaço de carne? Não é legal transar sem camisinha, se existir alguma chance de você ser HIV positivo. Mesmo que o outro cara diga que tudo bem - não está tudo bem. Se ele não se cuida, então você terá que se cuidar." E também na (figura 12) que mostra o um diálogo entre um grupo de jovens sobre o sexo sem camisinha.

Figura 11- "in bed together" (1997)

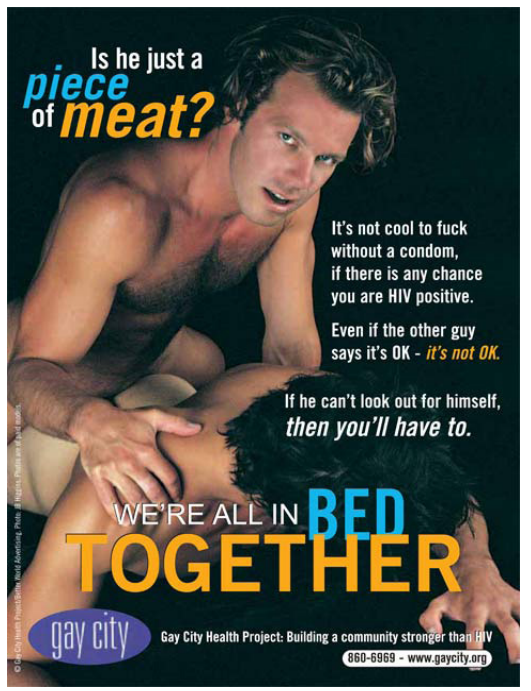

Fonte: San Francisco Aids Foundation (2012). 
Figura 12 -"Without a condom" (1997)

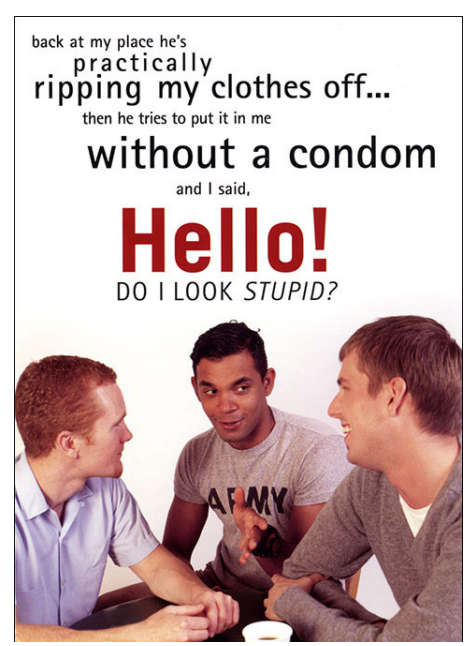

Fonte: San Francisco Aids Foundation (2012).

\section{$O$ século $X I X$}

Após alguns anos do surgimento das novas drogas para o tratamento da infecção pelo HIV, foi ficando claro que esses medicamentos não representavam uma cura de imediato, mas sim, uma nova perspectiva de tratamento, que possibilita uma vida razoavelmente saudável havendo o controle rígido dos indicadores da evolução da doença e se necessário a ingestão dos medicamentos.

Porém, o surgimento de um tratamento eficaz e a diminuição do número de mortes diminuiu a conscientização do uso do preservativo e faz muitas pessoas confiarem no tratamento e na testagem como mecanismo eficaz de controle da epidemia.

E neste momento que surgem campanhas de prevenção que procuram dar conta desta nova demanda explorando a extenuante rotina de quem faz uso do coquetel e de seus efeitos colaterais como é o caso da (figura 12) que faz parte de uma série de cartazes que utiliza como exemplo, os efeitos colaterais mais comuns relacionados ao uso dos medicamentos antiretrovirais. Este cartaz mostra um homem com lipoatrofia abdominal, ou seja, o deslocamento de gordura de diversas partes do corpo que resulta em um acúmulo anormal de gordura no abdome, ou no pescoço. O cartaz diz: "Fico chateado quando vejo que quem não é HIV positivo acha que não é tão ruim assim. Eu estou feliz de estar vivo, mas nada substitui ser HIV negativo. Se você não tem, não pegue!". 
Figura 12 - "HIV not fabulous" (2001)

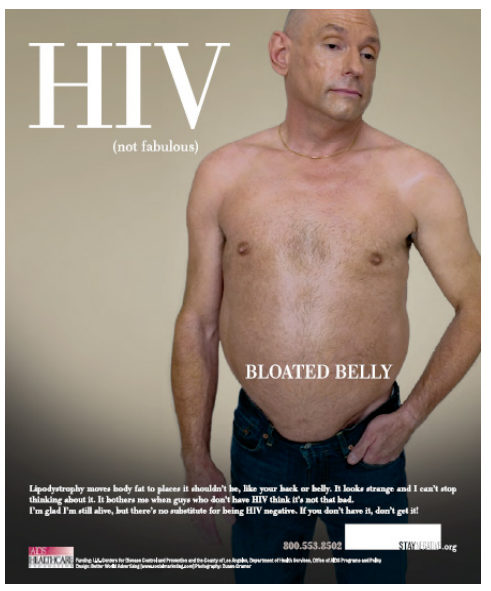

Fonte: San Francisco Aids Foundation (2012).

Figura 13 - "barebacking" (2001)

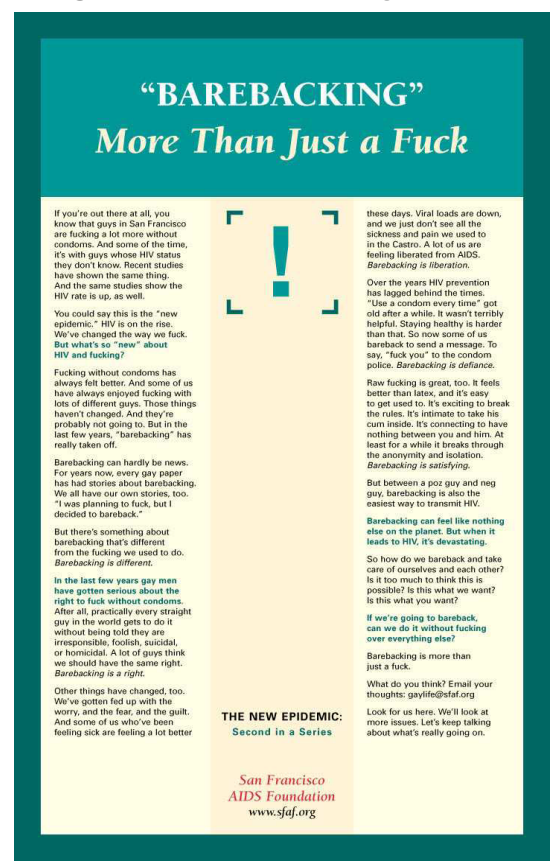

Fonte: San Francisco Aids Foundation (2012).

Além disso, outras práticas ligadas ao vírus foram surgindo, aos poucos. Um exemplo disso é o barebacking ${ }^{6}$ a prática de sexo sem preservativo, preferencialmente com múltiplos parceiros, ignorando-se o risco da possível contaminação pelo vírus.

A temática do bareback surge em algumas campanhas como na (figura 13) explica em um longo texto os detalhes e riscos das práticas do barebacking. Já na (figura 14) um texto em caixa alta com fontes bold diz: "ativos que fazem 60 termo vem da palavra bareback que significa "montar sem sela", mas que foi adaptado para os meios homossexuais para designar o sexo sem preservativo. 
bareback devem ser negativos". O título dessa série de cartazes é: "como você sabe, o que você sabe?".

Figura 14 - "barebacking more than just a fuck" (2001)

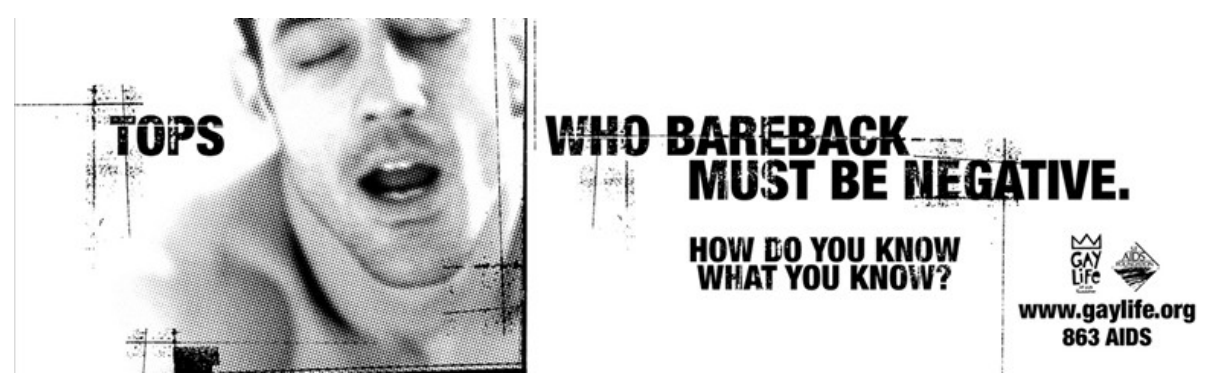

Fonte: San Francisco Aids Foundation (2012).

\section{CONCLUSÃO}

Normatizar ou procurar estabelecer um padrão gráfico para as campanhas de prevenção ao HIV através do tempo se mostrou uma tarefa difícil, talvez até impossível. Isso acontece provavelmente porque a forma das campanhas, sua linguagem visual e as ferramentas gráficas utilizadas em sua composição, atendem a diferentes demandas que foram sendo criadas com os diferentes rumos da epidemia.

Uma vez que a maioria das campanhas de prevenção é veiculada por órgãos governamentais e organizações sem fins lucrativos, existem muitos fatores "externos" ao designer que decidem o conteúdo gráfico do que foi ou será veiculado, o período e o público da veiculação. O governo brasileiro, por exemplo, faz duas campanhas anuais uma no carnaval e outra no dia mundial da luta contra a Aids. No Carnaval a ênfase é sempre na camisinha, e no dia mundial ela recaí sobre vivência com o vírus. A alternativa a prevenção governamental no Brasil, são as ONGS que dependem de verbas e doações, o que pode tornar inconstante a veiculação por parte dessas organizações. Apesar dessas dificuldades já há algum tempo, existem algumas iniciativas por parte de ONGS e da sociedade civil que procuram informar os diversos nichos da sociedade, atendendo às diferentes necessidades de prevenção, porém isso poderia ser ampliado.

Apesar da Política Brasileira de AIDS (2012)7 servir como referência para vários países tendo mostrado êxito em uma série de aspectos ligados a epidemia, alguns pontos ainda podem e devem ser trabalhados com mais $7 \quad$ Os resultados mais recentes da Política Brasileira de Aids (2012). 
cuidado. A prevenção é um bom exemplo disso. Ao contrário do protocolo de produção e distribuição de medicamentos, nossas campanhas de prevenção governamentais têm muitas vezes objetivos muito amplos, e nem sempre estão tão atualizadas como as de outros países. Pensando nisso, porque não aproveitar do gancho da formação de base do designer que o coloca constantemente diante da solução de problemas e lacunas, para pensar novos sistemas e modelos para a prevenção e gestão em saúde. Esse trabalho poderia ser colocado em prática através de equipes multidisciplinares trabalhando em parceria com profissionais de diversas áreas, pensando e materializando alternativas para a prevenção e os cuidados em saúde. 


\section{REFERÊNCIAS}

LEMOS, J. F. de. 0 risco em cena: análise das campanhas de prevenção à AIDS da MTV Brasil. Dissertação de mestrado. Instituto de Medicina Social. Ciências Humanas e Saúde UERJ: Rio de Janeiro, 2006.

NASCIMENTO, D. R. A Face visível da Aids. Historia, Ciências, Saúde: Manguinhos. Rio de Janeiro, v. 1. n. 1, 1997.

POLÍTICA Brasileira de AIDS: principais resultados e avanços • 1994 - 2002. Disponível em:<http://bvsms.saude.gov.br/bvs/publicacoes/ politica_94_02.pdf >. Acesso em: 10 jul. 2012.

POLLAK, M. Os homossexuais e a AIDS. São Paulo: Estação Liberdade, 1990.

POLLAK, M. A homossexualidade masculina, ou felicidade no ghetto? In ARIÉS, Philippe; BÉJIN, André (Org.). Sexualidades Ocidentais. Lisboa: Contexto, 1983. p. 51-73.

SAN FRANCISCO AIDS FOUNDATION. Prevention. Disponível em:<http://www.sfaf.org/>. Acesso em: 10 jul. 2012.

Recebido em: 03/03/2013. Aceito em: 28/04/2013. 